\title{
Preferences of Persons with Type 2 Diabetes for Diabetes Self-Management Education Interventions: An Exploration
}

\author{
Lifeng Fan1, Souraya Sidani² \\ ${ }^{1}$ Toronto Chronic Diseases Centre, Toronto, Canada \\ ${ }^{2}$ School of Nursing, Ryerson University, Toronto, Canada \\ Email: lifeng.fan@gmail.com
}

How to cite this paper: Fan, L.F. and Sidani, S. (2017) Preferences of Persons with Type 2 Diabetes for Diabetes Self-Management Education Interventions: An Exploration. Health, 9, 1567-1588. https://doi.org/10.4236/health.2017.911115

Received: May 10, 2017

Accepted: Oct0ber 27, 2017

Published: October 30, 2017

Copyright ( 92017 by authors and Scientific Research Publishing Inc. This work is licensed under the Creative Commons Attribution International License (CC BY 4.0).

http://creativecommons.org/licenses/by/4.0/

\begin{abstract}
Objectives: Treatment preferences affect treatment engagement, adherence and outcomes. There is limited knowledge of patients' preferences for Diabetes Self-Management Education (DSME). This study explored the preferences of Canadians with diabetes for components, mode and dose for implementing DSME interventions. Methods: A cross-sectional design was used. Adults with diabetes completed a questionnaire to assess participants' preferences for components (i.e. content), mode (i.e. teaching strategies, delivering formats) and dose (i.e. number and length of sessions) of DSME. Descriptive statistics were used to analyze the data. Results: Participants $(n=100)$ were middle-aged men and women, who had diabetes for 6.1 years and previously received (95.0\%) DSME. They indicated preference for DSME to include a combination of educational, behavioral and psychological components; to be delivered in individual, face-to-face sessions (4 sessions, 60 minutes each, given monthly) that allowed discussion with one diabetes educator to develop and carry out a care plan. Conclusions: Diabetes educators may consider eliciting patient's preferences and tailoring DSME to fit patients' preferences. Delivering interventions that are consistent with patients' preferences increases their motivation to engage in intervention, satisfaction and adherence to treatment and achievement of desired outcomes.
\end{abstract}

\section{Keywords}

Type 2 Diabetes, Preferences, Diabetes Self-Management Education, Interventions, DSME, Diabetes Education

\section{Introduction}

Type 2 diabetes is a chronic disease that affects a large number of adults world- 
wide. Its prevalence in Canada is increasing at an alarming rate. It is estimated that $6.8 \%$ of adult Canadians (about 2.4 million) had diabetes in 2009. By 2019, that number is expected to increase to 3.7 million [1]. The target of diabetes management is to achieve glycemic control and to maintain blood glucose, blood pressure, and cholesterol levels, and weight within acceptable ranges in order to prevent diabetes chronic complications such as heart diseases, stroke, kidney diseases, eye problems, and foot ulcers [1] [2].

People with diabetes are responsible for the management of their disease on a daily basis. They have to actively engage in multiple self-management activities to achieve glycemic control and prevent complications. Self-management activities include: carefully selecting food, engaging in regular physical activity, self-monitoring of blood glucose, taking medications (oral pills or insulin injection) as prescribed and adjusting the medications dose as needed, managing stress and emotional distress, screening complications, and implementing strategies to prevent the occurrence of complications [1]. Diabetes self-management education (DSME) refers to the process of teaching people with diabetes about the application of self-management activities [3]. The goal of DSME is to assist in acquisition of the knowledge, skills and abilities necessary for practicing diabetes self-management [4]. DSME provides people with diabetes the knowledge and skills needed to make lifestyle changes required to successfully manage this disease, and provides the critical elements to assist people with diabetes to guide these decisions and activities; it has been demonstrated to improve clinical outcomes [5] [6] [7].

Although DSME is highly recommended and accessible, patients with diabetes demonstrate low utilization and high attrition rates from DSME programs. These suboptimal rates may be related to low satisfaction, and the format for delivering the educational sessions; in fact, patients found the content not quite responsive to their specific self-management needs [8] [9]. In other words, DSME programs, as designed, may not fit with patients' preferences. Yet, evidence indicates that preferences affect motivation to engage in and adhere to treatment, satisfaction with treatment and consequently outcomes achievement [10]. Preferences denote patients' choices of intervention, that is, the intervention they want to receive to manage the presenting clinical problem [11].

A key element of patient-centered care is involving patients in the development of interventions in a way that is consistent with their preferences [12] [13]. Accordingly, it is necessary to account for patient preferences in designing educational and behavioral interventions aimed at enhancing self-management in diabetes [14]-[19]. A few recent studies examined patients' perception of interventions for diabetes self-management [20] [21] [22]. These studies targeted patients with different socio-cultural backgrounds and assessed their views of specific aspects of education or support interventions. The results showed that most diabetes patients report an interest in receiving diabetes self-management edu- 
cation, but preferences for strategies of delivery of self-management support (telephone support, group medical visits, one-on-one peer support, and Internet-based support etc.) vary by ethnicity, language proficiency, and self-reported health literacy. Healthcare providers should consider offering a range of diabetes self-management education and support services to meet the needs of their diverse patient populations. However, there is limited knowledge of the preferences of Canadian persons with diabetes for the following aspects of DSME interventions: components or types of intervention (i.e. education, psychological, behavioral), mode of delivery (i.e. teaching strategies; formats for delivery); dose (i.e. number, duration, and frequency of sessions), and type of interventionist responsible for implementing the interventions. Understanding patients' views on these aspects is essential for designing DSME interventions that are acceptable to and consistent with the preferences of persons with diabetes. Offering interventions that are responsive to their preferences is expected to improve their motivation to participate actively in the intervention activities, adherence or performance of self-management activities, and consequently improvement in outcomes [11] [12].

The specific objectives of this study were to describe the acceptability and preferences of adult Canadians with type 2 diabetes for the following aspects of DSME interventions: components (i.e. education, psychological, behavioral), mode of delivery (i.e. teaching strategies, use of teaching aids, formats, follow-up modes, timing, group size), dose (i.e. number, length and frequency of sessions), and type of instructors responsible for providing DSME.

\section{Methods}

Design, sampling and sample size: A cross-sectional design was used to examine preferences for DSME interventions. Eligible and consenting participants were requested to attend a data collection session to complete study questionnaires assessing the variables of interest. The sample of convenience included 100 patients with type 2 diabetes. This sample size was adequate to address the descriptive objective of this study.

Setting and participants: The study took place in primary healthcare settings including a family health team (FHT) centre and Toronto Chronic Diseases Centre (TCDC) after getting the local ethics approval. Participants referred by their family physicians to receive care from internists and diabetes educators at diabetes management teams in the two centers in Toronto. The target population consisted of adult patients with type 2 diabetes. Persons were eligible if they: 1) had a confirmed diagnosis of type 2 diabetes; 2 ) were 18 years of age or older; 3) able to read and understand English; and 4) non-institutionalized, residing in the catchment area served by the clinics.

\subsection{Variables Measures}

Participants' socio-cultural and clinical characteristics. The socio-cultural 
characteristics included age, gender, education, employment status, and were assessed with standard questions. The clinical characteristics involved: duration of diabetes, metabolic control levels including hemoglobin A1c (HbAlc), blood pressure, low-density lipoprotein (LDL) and body mass index (BMI), and prior exposure to diabetes education. The researcher obtained the latest HbAlc and LDL laboratory reports from the participants' medical records, after securing their consent. The researcher assessed blood pressure with an Omron blood pressure monitor, on the participant's right arm, while in a seated position, and recorded the systolic blood pressure (SBP) and diastolic blood pressure (DBP) readings. The researcher also measured the participant's weight and height with a standard standing measuring scale, after calibrating it. BMI was calculated by measuring participants' weight $(\mathrm{kg})$ and height $(\mathrm{m})$ and applying the formula $\left\{\right.$ weight $(\mathrm{kg}) /$ height $\left.(\mathrm{m})^{2}\right\}$ to compute BMI. Participants indicated the actual number of years they have been diagnosed with diabetes (i.e. duration of diabetes) and whether or not they have had received diabetes education and information related diabetes management (prior exposure to diabetes education).

Preferences for DSME interventions. The researcher developed a set of questions to assess participants' preferences for DSME intervention types, teaching strategies and methods, delivery formats and approaches, teaching aids use, follow-up modes, dose, timing for providing the intervention sessions, group size, and instructor involvement. The items were derived from the literature review previously conducted [3] [4]. The questions were pilot tested for comprehension with 5 persons with type 2 diabetes and 2 nurses. Minor changes were made based on their feedback to clarify the description of different aspects of the DSME interventions. The content of the questions is detailed next.

Intervention types were: 1) educational intervention, which refers to interventions in which patients with diabetes primarily receive information from healthcare providers and aim to improve patients' knowledge of diabetes self-management; 2) behavioral intervention, which refers to interventions that focus on active skills training and emphasize acquisition of skills associated with lifestyle changes and implementation of a diabetes self-management regimen, such as diet, physical activity, blood glucose monitoring, foot care, and weight management; 3) psychological intervention, which refers to interventions in which the primary goal is to address stress and negative mood states, and to promote coping skills such as relaxation exercises and social support; and (4) combination of all 3 intervention types.

Teaching strategies used to convey DSME content included: 1) written material in the form of brochure/pamphlet that can be handed out to patients; 2) online/web based; 3) video; and 4) lecture presentation; and 5) interactions with instructor.

Teaching methods for providing DSME were divided into: 1) didactic lecture, where the educator conveyed diabetes-related information to patients, the didactic lectures were often characterized by limited interaction between instructor 
and participants and may involve a combination of distributing written materials, watching a video or attending formal individual or group sessions; 2) discussion sessions, which consisted primarily of active patients' involvement in the learning process through exchange of information; 3) hands-on practice of the skills learned such as self-monitoring of blood sugar, choosing food items, and insulin injection; and 4) development of a care plan, where participants worked with the educator to develop and carry out a care plan (e.g. using problem solving or individualized goal-setting negotiation).

Teaching aids used to enhance the delivery of DSME intervention were: 1) power point slides to illustrate points or skills; 2) teaching tools such as food menu and labels; and 3) demonstration of how to use materials and supplies such glucometer and insulin pen. Participants were also asked if they prefer to not use any teaching aids.

Mode of delivery related to format and approach. Format reflected the number of participants attending a given intervention session including one-on-one teaching session, or group teaching session. Approach indicated the delivery of DSME intervention either by face-to-face on site or via telephone communication with diabetes educators, or a combination of these two approaches.

Follow-up modes represented participants' preferences for ways to complete follow-up booster sessions after receiving DSME interventions; these were 1) on-site visit: patients come to the clinic and meet the diabetes educator in person to discuss relevant self-management information; 2) phone-call: diabetes educator contacts patients by phone; and 3) regular mail: patients complete pertinent self-management tools and documents and mail them back to the diabetes educator.

Dose of DSME intervention was described in terms of number of sessions; duration of each session; and frequency of sessions. Participants were required to indicate their preferences for each by writing down the respective numbers.

Group size preferred by participants was assessed by having them select the number of persons to include in a group teaching session, which ranged from 4 - 6, 7 - 15, 16 - 25, and 25 persons or more for each option in this study.

Timing indicated participant's preferences for days of the week (weekdays or weekends) and time of the day (mornings, afternoons or evenings) on which the intervention sessions are offered.

Instructor involvement referred to the number of instructors (one or more) to facilitate the sessions and carry out the teaching activities. Instructor related to the type of healthcare providers responsible for facilitating the sessions such as: doctor, diabetes nurse educators, dietitians, other providers, and persons with diabetes.

\subsection{Data Collection and Data Analysis}

Eligible and consenting participants were requested to complete the questionnaire on their own. 
Completing the questionnaires took about 20 minutes. The researcher checked the completed questionnaires to avoid missing data after participants completed them. The data analysis was carried out using SPSS (version 22.0) for Windows. Descriptive statistics were used to describe the sample in terms of socio-cultural and clinical characteristics, and preferences for the different aspects of DSME interventions.

\section{Results}

Participation rates. A total of 121 eligible patients with diabetes were invited to the study. Of these, 100 patients (82.6\%) completed the study, and 21 patients (17.4\%) declined participation. The reasons for refusal were time conflict with work or housework ( $\mathrm{n}=11,52.4 \%$ of those who declined) and no interest in the study $(\mathrm{n}=2,9.5 \%) ; 8(38.1 \%)$ patients gave no reason.

Participant's socio-cultural characteristics. The participants' characteristics are summarized in Table 1 . Participants were adults with type 2 diabetes with an average age of 58.9 years $(S D \pm 10.1$, range $=38-85)$. The years of formal education ranged between 6 and 19, with a mean of 14.09 years $(S D=2.37$ ), with most having attended college or university. The sample consisted of slightly more men $(55 \%)$ than women $(45 \%)$. Most participants were married or partnered $(72 \%)$, and employed (68\%) either full-time or part-time. They varied in ethnicity with most self-identifying as South East Asians.

Participant's clinical characteristics. As showed in Table 1, participants had diabetes for an average of 6.16 years $(S D=5.92)$; about one-third were newly diagnosed ( $<1$ year) with diabetes. They had an average BMI of $30.08 \mathrm{~kg} / \mathrm{m}^{2}$ (SD $=5.84), \mathrm{LDL}$ of $2.49(\mathrm{SD}=1.25), \mathrm{SBP}(120.44, \mathrm{SD}=13.26)$ and $\mathrm{DBP}(69.16, \mathrm{SD}=$ 8.27). The mean FPG was $7.46 \mathrm{mmol} / \mathrm{L}(\mathrm{SD}=1.65)$ and $\mathrm{HbAlc}$ was $8.25 \%(\mathrm{SD}=$ 1.66), Overall, more than $50 \%$ participants did not reach the glycemic control targets for $\mathrm{HbAlc} \geq 7.0$ (76\%). The majority of participants (95\%) indicated that they previously received diabetes education, mainly through attending diabetes education sessions (94\%), and reading pamphlet/booklets (78\%). Participants indicated engagement in the following diabetes management activities: taking oral medications (80\%), using insulin (20\%), having regular physical activities (95\%), healthy eating (97\%), self-monitoring of blood sugar (96\%), and taking care of feet (96\%).

Preferences of DSME interventions. Table 2 presents the percentage of participants indicating preferences for the DSME interventions' types, mode and dose of delivery, and interventionists.

Preferences for intervention types. A small number of patients preferred educational $(n=14)$ and behavioral $(n=8)$ interventions, whereas the majority (78.0\%) chose a combination of DSME interventions.

Preferences for teaching strategies. Participants expressed preference for more than one teaching strategy. Most participants (88\%) preferred interactive learning with diabetes educators; $64 \%$ selected lectures presentation, and $58 \%$ chose 
Table 1. Participant personal and clinic characteristics.

\begin{tabular}{|c|c|c|}
\hline Variable & $\begin{array}{c}\mathrm{n} \text { or } \\
\text { mean } \pm \mathrm{SD}\end{array}$ & $\%$ \\
\hline Age (years) & $58.9 \pm 10.1$ & \\
\hline \multicolumn{3}{|l|}{ Gender } \\
\hline Male & 55 & 55.0 \\
\hline Female & 45 & 45.0 \\
\hline \multicolumn{3}{|l|}{ Marital status } \\
\hline Single & 11 & 11.0 \\
\hline Married/partnered & 72 & 72.0 \\
\hline Divorced & 14 & 14.0 \\
\hline Widowed & 3 & 3.0 \\
\hline $\begin{array}{l}\text { Receiving education (years) } \\
\text { educational levels }\end{array}$ & $14.0 \pm 2.3$ & \\
\hline Less than school graduate & 1 & 1.0 \\
\hline High school graduate & 26 & 26.0 \\
\hline Technical training & 9 & 9.0 \\
\hline Some college/university & 23 & 23.0 \\
\hline College/university graduate & 41 & 41.0 \\
\hline \multicolumn{3}{|l|}{ Ethnicity/cultural background } \\
\hline South East Asians & 30 & 30.0 \\
\hline South Asians \& East Asians & 22 & 22.0 \\
\hline Europeans & 10 & 10.0 \\
\hline Canadians & 21 & 21.0 \\
\hline Africans & 5 & 5.0 \\
\hline Caribbean & 12 & 12.0 \\
\hline \multicolumn{3}{|l|}{ Employment status } \\
\hline No & 32 & 32.0 \\
\hline Yes & 68 & 68.0 \\
\hline Part-time & 17 & 25.0 \\
\hline Full-time & 51 & 75.0 \\
\hline
\end{tabular}




\section{Continued}

\section{Diabetes characteristics}

Duration of diabetes(year)

$6.16 \pm 5.92$

Duration of diabetes ( $\leq 1$ year)

FBG $(\mathrm{mmol} / \mathrm{L})$

$7.46 \pm 1.65$

HbAlc (\%)

$8.25 \pm 1.66$

$\mathrm{LDL}(\mathrm{mmol} / \mathrm{L})$

$2.49 \pm 1.25$

$\mathrm{SBP}(\mathrm{mmHg})$

$120.44 \pm 13.26$

DBP (mmHg)

$69.16 \pm 8.27$

BMI $\left(\mathrm{mg} / \mathrm{m}^{2}\right)$

$30.08 \pm 5.84$

\section{Received diabetes education}

Yes

No

Person provided diabetes education (chose all that applied)

Doctor

Diabetes educator

Dietitian

Other healthcare provider
Form used to give diabetes education (chose all that applied)

Pamphlet/booklet

Video

Internet

Individual session

Group session

Attended individual sessions $\geq 1$

Attended group sessions $\geq 1$

Methods used to manage diabetes (chose all that applied)

Take pills

Take insulin

Physical activity

Eat healthy

Relax to manage stress

Take care of my feet

Self-monitoring blood sugar
80

20

46.0

98.0

27.0

23.0 
Table 2. Patient's preferences for diabetes self-management education intervention.

\begin{tabular}{|c|c|c|}
\hline Preferences for DSME & $\mathrm{n}$ & $\%$ \\
\hline \multicolumn{3}{|l|}{ Types } \\
\hline Diabetes self-management knowledge educational intervention & 14 & 14.0 \\
\hline Lifestyle behavioral educational intervention & 8 & 8.0 \\
\hline Psychological educational intervention & 0 & 0.0 \\
\hline Combination of types & 78 & 78.0 \\
\hline \multicolumn{3}{|l|}{ Teaching strategies (chose all that applied) } \\
\hline Pamphlet/booklet & 58 & 58.0 \\
\hline Video & 19 & 19.0 \\
\hline Computer/internet & 15 & 15.0 \\
\hline Lecture/presentation & 64 & 64.0 \\
\hline Interaction learning & 88 & 88.0 \\
\hline \multicolumn{3}{|l|}{ Teaching methods (chose all that applied) } \\
\hline Didactic lecture & 64 & 64.0 \\
\hline Discussion & 30 & 30.0 \\
\hline Hands-on practices opportunity to practice what is learned & 17 & 17.0 \\
\hline Work with the educator to develop and carry out a care plan & 64 & 64.0 \\
\hline \multicolumn{3}{|l|}{ Teaching aids (chose all that applied) } \\
\hline Using power point slides/projector to guide the teaching & 88 & 88.0 \\
\hline Using teaching tools (food models, unhealthy foot models, etc.) & 94 & 94.0 \\
\hline Demonstrating use of glucometers, and insulin pen, etc. & 81 & 81.0 \\
\hline Do not use any teaching aids & 0 & 0.0 \\
\hline \multicolumn{3}{|l|}{ Delivery formats } \\
\hline One-on-one teaching sessions & 74 & 74.0 \\
\hline Group teaching sessions & 26 & 26.0 \\
\hline \multicolumn{3}{|l|}{ Delivery approaches } \\
\hline Face to face meeting with the diabetes educator & 82 & 82.0 \\
\hline Telephone calls communication with diabetes educator & 8 & 8.0 \\
\hline Multi-delivery approaches & 10 & 10.0 \\
\hline \multicolumn{3}{|l|}{ Follow-ups modes } \\
\hline Follow-up visit & 81 & 81.0 \\
\hline Follow-up phone-call & 14 & 14.0 \\
\hline Follow-up by mail & 0 & 0.0 \\
\hline Follow-up by email & 5 & 5.0 \\
\hline \multicolumn{3}{|l|}{ Dose/intensity } \\
\hline \multicolumn{3}{|l|}{ Number of sessions } \\
\hline 1 session & 6 & 6.0 \\
\hline 2 sessions & 14 & 14.0 \\
\hline 3 sessions & 31 & 31.0 \\
\hline$\geq 4$ sessions & 49 & 49.0 \\
\hline
\end{tabular}




\section{Continued}

Length of the time for each session

$\leq 30$ minutes

3.0

30 - 60 minutes

60.0

60 - 120 minutes or more

34.0

120 minutes or longer

\section{Frequency}

All on one day

weekly

11.0

Biweekly (once every other week)

5.0

Monthly (once a month)

45.0

Every 2 - 3 months

27.0

More than 3 months

\section{Group size}

4 - 6 persons in a group $\quad 40$

$7-15$ persons in a group

55.0

16 - 25 persons in a group

$\geq 25$ persons or more

Date for attending DSME sessions

Weekdays

Weekends

Ok with any day
45.0

10.0

45.0

Timing for attending DSME sessions

Morning 40

Afternoon 30

Early evening

Ok with anytime

23

\section{Instructor involvement}

One instructor facilitates/completes one session teaching

Multi-instructors facilitate/complete one session teaching

Interventionist (all that applied)

Doctor

Nurse diabetes educator

Dietitian

Other healthcare providers
23.0

40.0 
written material in brochure or pamphlet to learn about DSME information.

Preferences for teaching methods. Both didactic lecture and working with diabetes educator to develop and carry out a care plan were equally popular (64\%) among patients with diabetes. Discussion with educators appealed to $30 \%$ of the participants.

Preference for teaching aids: Majority of participants indicated preference for using teaching aids to guide their leaning. Specifically, $88 \%$ of participants chose power point slides, $94.0 \%$ liked teaching tools, and $81 \%$ wanted educator's demonstration of how to use materials and supplies (e.g. glucometers and insulin pen).

Preference for delivery formats: The three-fourths of the participants (74\%) preferred one-on-one, whereas about a quarter (26\%) chose group teaching session as the format for delivering DSME interventions.

Preference for delivery approaches: Similarly, the majority of participants preferred a face-to-face (82\%) approach; only a few participants (8\%) chose telephone-calls, whereas $10 \%$ participants preferred the combination of these two approaches for delivering DSME interventions.

Preference for follow-up booster session modes. The majority of participants chose to have follow-up booster sessions by visiting diabetes educators (81\%) at the clinic; $14 \%$ desired phone-call with diabetes educators, and only 5\% participants selected completion of tools and documents as modes for their follow-ups with the diabetes educator. No participants chose follow-ups by regular mails.

Preference for intervention dose: For the number of sessions, $49 \%$ of the participants indicated preference to have the DSME interventions delivered in four or more sessions, and $31 \%$ chose to have 3 sessions. In terms of session duration, $60 \%$ of participants wanted each session to last $\leq 60$ minutes, and $34 \%$ preferred > 60 minutes. As to frequency of the sessions, $45 \%$ participants desired to have the sessions given once a month (i.e. monthly), and $27 \%$ every 2 - 3 months (i.e. quarterly), and $11 \%$ once a week (i.e. weekly).

Preference for group size: Over a half of participants (55\%) preferred to include 7 - 15 persons per group session, and 40\% wanted a smaller group comprised of 4 - 6 persons.

Preference for timing: More participants preferred to attend the intervention session on weekdays (45\%) than weekends (10\%), whereas the rest $(45.0 \%)$ selected both (i.e. weekdays and/or weekends). Most participants liked the morning (40\%) for attending the sessions, whereas 30\% and $7 \%$ preferred the afternoons and evenings, respectively; $23.0 \%$ had no preferred time.

Preference for instructor involvement: More participants preferred to have one instructor $(86 \%)$ than multiple instructors $(14 \%)$ to facilitate one session. The most commonly selected interventionists were diabetes nurse educators (98\%), followed by dietitians (40\%), doctors $(24 \%)$, other healthcare providers (14\%), and persons with diabetes (10\%). 


\section{Discussion}

This study focused on examining the preferences of patients with type 2 diabetes for types, mode and dose of delivering DSME interventions, as well as the interventionists responsible for facilitating the intervention sessions. The results provide guidance for designing DSME interventions that are consistent with patients' preferences.

\subsection{Preferences for Intervention Types}

Previous studies reported that most participants (60\% to 100\%) had preferences for their interventions [20]-[27]. The findings from this study showed that the majority participants $(78 \%)$ preferred a combination of educational, behavioral and psychological elements for DSME intervention, which is consistent with current trends in diabetes education. DSME is developing from a traditional didactic teaching method to involve multi-components, with combination of didactic and interactive teaching strategies that are modified to the patient's specific needs [3]. In a meta-analysis of DSME, over half (54\%) of the interventions in the review reported containing a mix of educational, behavioral, or psychological components, and these multi-component interventions were found to be most effective in increasing knowledge and improving diabetes metabolic control. Therefore education combined with specific behavioral change strategies produced the greatest benefits [3] and are demanded by Canadian patients with diabetes. The combination of educational, behavioral, and psychological component ensures coverage of didactic information and action-oriented elements that fit the needs of patients with diabetes in actively engaging and learning self-management activities; this in turn will assist them to achieve their metabolic targets [3] [4].

\subsection{Preferences for Teaching Strategies and Methods}

Only a single way is hard to meet patient's needs. Most patients preferred combination multiple methods to learn about self-management through interactions with diabetes educators that involve discussion, didactic lectures presentation, and one-on-one work with interventionist to collaborate in developing and carrying out a care plan to achieve their treatment targets.

Some patients also wanted written material to support learning. DSME plays a vital role in diabetes self-management however, how patient education is delivered may not fit with the preferences of Canadians with diabetes. Teaching methods have evolved, ranging from didactic lectures to combination of didactic lecture and patient-provider interactive discussion methods that maximize patients' active involvement in learning activities [28]. Lifestyle behavioral change, which is a major outcome parameter for DSME [29], is hard to achieve through didactic learning alone. A DSME intervention that aims to enhance self-management behavior has to involve patients as full participants in the process of learning [30]. The mixed teaching method has been found more effec- 
tive than either didactic or interactive teaching methods alone in improving knowledge, metabolic control and self-management behavior [3] [31]. Friedman et al. [32] reported that a combination of teaching strategies for the delivery of patient education was effective in increasing knowledge and enhancing satisfaction with the intervention; specifically the authors concluded that illustrations facilitated patients' understanding of written materials. In addition, culturally appropriate structured teaching, and teaching activities addressed to a patient's individualized situation were found to more effective than teaching that only provides general information to a patient or group of patients.

In our study, patients with diabetes liked the use of different teaching aids, including power point slides, teaching tools such as food models, and demonstrating use of glucometers and insulin pens etc., to promote learning about their self-management skills. Such aids have been found useful in enhancing learning, and are considered an effective teaching strategy in delivering patient education [32] [33]. In addition, study participants selected educator's demonstration of glucometers and insulin pen use, as means to enhance learning self-management. The findings of this study are consistent with the literature [32] [33] [34]. One meta-analysis [34] evaluated the effect of demonstrations on outcomes related to patient education. Based on the pooling of nine individual studies, demonstrations had a large effect size (0.79) for clinical outcomes compared to routine teaching. Demonstrations can be a useful teaching strategy in enhancing participant's learning if appropriate for the situation.

\subsection{Preference for Delivery Formats and Approaches}

In general, more participants preferred one-on-one, compared to group, teaching format. DSME has been delivered and implemented using a variety of methods. Group-based DSME has generally been found to be equally effective as individual DSME at improving diabetes-related outcomes. There is some evidence that group programs are more cost effective, result in greater treatment satisfaction, and are slightly better in supporting lifestyle changes [35] [36]. Hwee et al. reported a population-based cohort study in Ontario, Canada, and found that group self-management education was associated with less acute diabetes complications and some improvements in health outcomes. Their study suggested that group sessions can offer care to more patients with decreased human resource involvement, and may provide an opportunity to deliver less resource-intensive care that simultaneously improves patient care [37]. Our study's findings showed that the one-on-one teaching session format is well received by majority patients with diabetes with pervious exposure to diabetes education. Over one fourth participants preferred the group format. DSME given in individual session can be tailored to the patients' specific needs [3]. Individual teaching addresses individuals' specific health issues and fit patients' learning needs; it involves them in interactive discussion geared toward developing a plan of action that is tailored toward achieving their personal metabolic 
targets. This point is supported by empirical evidence showing that individual teaching had a significant benefit in improving glycemic control in studies involving participants with poor glycemic control at baseline levels [38]. Mixed DSME interventions generally included group sessions covering basic knowledge and problem-solving skills, combined with individual sessions with an educator; this format appeared to be more effective in increasing knowledge and improving metabolic control outcomes [3]. Both individual and group settings have been used for cognitive-behavioral interventions, but there is no definitive conclusion as to which is superior [1] [3] [39]. In general, group formats have been found to be more effective for weight loss and short-term glycemic control, whereas group combined with individual follow-up sessions have resulted in better A1C levels than either format alone [40].

Most participants in the present study preferred face-to-face approach for delivering DSME interventions. Face-to-face approaches have been found most effective for enhancing knowledge and metabolic control, while mixed delivery strategies showed a moderate effect size for knowledge. Both patients and diabetes educators were involved in interactive teaching and learning activities, which maximized the effects of DSME interventions [3]. Nearly one fifth of patients preferred combination of face-to face and telephone calls communication with diabetes educator in this study. Telephone contact seems to be an effective way for delivering DSME and assisting patients in increasing their knowledge and self-efficacy to implement self-management behaviors [41], and therefore actual engagement in self-management behaviors and diabetes metabolic control levels. Telephone contact is considered a convenient, simple, time-saving and less costly way for providing DSME; it could also be helpful in reaching those who have barriers to accessing DSME interventions. No particular delivery strategy (e.g. face-to-face, phone, or mixed) appears to generate consistently superior health outcomes among patients with type 2 diabetes; however, larger effect sizes have been found for strategies that involve personal contact with healthcare providers, either via face-to-face interactions or by telephone [1] [3]. It was found that a mix of didactic and interactive teaching methods, and of group and individual sessions for delivering DSME interventions, is most effective in patients with type 2 diabetes [1] [3].

\subsection{Preference for Intervention Dose}

In general, participants selected 3 or 4 sessions, delivered on a monthly basis, as optimal for delivering DSME interventions, with a rather short duration (about one hour) for each session. The dose of DSME intervention is important to consider as it affects the intervention outcomes. Latest studies that examined associations of intervention dose with behavior changes concluded that interventions of longer duration may be required to influence complex lifestyle behaviors such as physical activity level and diet changes such as fat and fiber intake [42]. The findings from a weight loss study indicated that increased dose of intervention 
was related to greater weight loss [43]. In general, DSME interventions with more sessions and a longer duration yielded greater effect sizes for increasing diabetes self-management knowledge and improving metabolic control indicators for patients with diabetes [3]. Other studies have also shown that interventions with a longer duration have larger effects than shorter ones [44] [45]. Preferences for DSME intervention dose, as expressed by majority participants in this study, are basically consistent with ideal session number as proposed by healthcare providers; three sessions are suggested to cover self-management knowledge, lifestyle behaviors, and stress management, with about 1 - 1.5 hours of duration for each session. As well, the dose they preferred may be convenient and suitable to them, particularly that most patients were employed.

In this study, participants preferred to have follow-up booster sessions by visiting diabetes educators. This is consistent with their preference for face-to-face sessions. Follow-up booster sessions play important roles in diabetes management. Incorporating follow-up booster sessions enhances the effectiveness of DSME interventions in assisting patients maintain the desired lifestyle behaviors changes, and adjust medications toward to reaching the metabolic targets; this is because lifestyle behavior changes and improvements in diabetes management are not self-sustaining, need to be adjusted with modifications in one's condition; that is, initial benefits of DSME intervention may fade by the time of follow-up [46]. In addition, the lifelong and progressive nature of diabetes means that effective diabetes self-management interventions must provide ongoing follow-up booster sessions and supporting activities [47].

\subsection{Preference for Group Size}

The participants preferred one-on-one sessions but if the diabetes education intervention was to be in a group format, they would prefer a small group DSME session. According to Mensing and Norris [48] a group is "a gathering or an assembly of persons with a common interest." It was suggested a group size of 2 - 20 members, with an average of 10 participants, is ideal for patient education classes [35]. Compared to individual approaches, small groups typically promote more discussion, sharing of information and experience, interaction and interpersonal dynamics between healthcare providers and patients [48]. Learners and instructors would report more connectedness and more instructor compliance in smaller groups than in larger group [49]. In addition, the small group teaching settings can facilitate behavioral changes through processes such as social modeling or problem-based learning, which are not triggered in individual sessions. Studies indicated that group sessions with more than eight persons were not convenient in meeting individual needs, such as in measuring blood glucose blood pressure and weight, and reviewing food, physical activities, medications, and blood glucose records. Larger group sizes may limit the opportunities for individual interactive activities and require a greater amount of didactic teaching, therefore decrease the effects of the DSME interventions [37]. 


\subsection{Preference for Timing}

The present study's findings showed that nearly a half of participants preferred to attend DSME interventions at weekdays, and one fifth of participants like to attend DSME interventions at weekends. Most participants indicated their preferences for attending sessions in the morning or afternoons rather than the evening. The timing of attending class is associated with participants' availability, especially for employed people. To maximize attendance and minimize attrition, the delivery of DSME programs should be arranged at a variety of dates and time to enhance their convenience to most patients. Surveys of health care providers in the United States and Canada have suggested that barriers to DSME program attendance include patient unwillingness, programs' location, languages of service, operating hours, and insurance coverage in US [50] [51] [52]. Therefore, the time for delivering DSME programs is one of barriers to DSME programs' utilization especially among employed patients [53]. Offering interventions at a time that fits with patients' preferences can increase attendance rate, decrease withdrawal from the programs, and in turn, enhance clinical outcomes.

\subsection{Preference for the Instructor Involvement}

The findings of this study indicated that participants preferred to have one instructor facilitate the one DSME intervention session. Patients may become familiar and more comfortable with one instructor. Getting and keeping participants engaged is perhaps one of most important steps in creating successful learning outcomes. Patients who become familiar with the instructor, may feel comfortable with the instructor's teaching styles, rhythm and pace, which may fit with their learning interests, and increase interactive discussion and active involvement in learning activities; also, the instructor may offer more frequent feedback throughout the learning process; in turn, this can improve retention of appropriate information and outcomes [54].

In this study, participants preferred to have diabetes nurse educators (98.0\%), dietitians $(40.0 \%)$, doctors $(24.0 \%)$, and other healthcare providers $(14.0 \%)$ as instructors facilitating the DSME. A multidisciplinary diabetes education team including multiple-instructors is often involved in delivering DSME with each instructor responsible for teaching one session covering topics consistent with their expertise. The involvement of multiple instructors in DSME allows participants to engage with differing learning aspects, and be exposed to knowledge and skills of more than one instructor; therefore, patients may develop a better understanding of knowledge, skills and abilities they need [55]. The ideal DSME intervention program comprises more than one educator and offers a patient-focused approach to diabetes self-management knowledge and skills. Since many diabetes complications could be prevented or delayed by assisting patients in achieving their glycemic control, blood pressure and lipids levels at targets, it is important that people with diabetes understand the roles of diet, exercise, and 
insulin/oral pills in the management of their diabetes. The properly educated people with diabetes can learn to adjust medications, to change diet, or to modify exercise regimens based on results of home blood glucose-monitoring to achieve treatment targets. A multidisciplinary diabetes education team approach to educating patients with diabetes would be useful as patients will learn relevant skills from expert team members [56]. This is consistent with the preferences and needs of patients who participated in this study.

\subsection{Implications for Practice and Research}

Asking patients to select treatment is consistent with patient-centered care. Findings from this study indicated that patients with type 2 diabetes have preferences for the types, modes and dose for implementing DSME interventions. The key options be on the menu of DSME that have emerged from this data is that health care providers need to assess patient's preferences and needs for DSME programs before delivering the DSME interventions, to tailor and deliver the program that fit patients' needs and preferences. In other words, healthcare providers should be provided with relevant knowledge and information, allow patients to express their preferences for their treatment options, and to tailor DSME interventions to patients' preferences, so that patients with type $2 \mathrm{di}$ abetes will actively attend, adhere to treatment, and improve health outcomes.

This study used a convenience sample of 100 patients with diabetes; the small sample size and the potential for self-selection bias limit the generalizability of findings to the adult patients with type 2 diabetes, and the limitations also include not rank preferences. Future research should replicate the study with a large sample of patients with type 2 diabetes, with including ranking preferences, and explore the association between patient expressed preferences for DSME interventions and patients' personal and clinic factors including age, gender, educational levels, employment status, and duration, previous exposure to diabetes education, and severity of diabetes since this factor may influence individuals' preferences for DSME interventions. However, the findings provide some directions for the design of DSME interventions; these could include a combination of educational, behavioral, and psychological components, given in 3 sessions or more, in face-to-face format, which allows tailoring of the information to the individual patients' needs. Future research needs to further examine the feasibility of the delivery of DSME that tailors to all or most patient's preferences. Future research also needs to explore the effectiveness of delivering tailored DSME interventions based on patients' preferences, and preferred options given our current climate of limited resources within the healthcare system.

\section{Conclusion}

In summary, the preliminary findings indicate that patients with type 2 diabetes expressed preferences when given the opportunity to choose their preferred DSME intervention programs, as they have many issues related to diabetes 
self-management that need to be addressed on daily bases. Health care providers should consider eliciting patient's preferences during educational sessions and tailor an individualized diabetes education plan to fit their preferences regarding teaching strategy, delivering format, follow-up modes, does, and timing of DSME intervention. Delivering DSME interventions that are consistent with patients' preferences increases the patients' motivation to engage in and adhere to DSME intervention, satisfaction with care, adherence to intervention protocol and consequently achievement of desired diabetes metabolic control outcomes. Future research needs to examine the feasibility, effectiveness and influences factors of delivering tailored DSME interventions based on patients' preferences given the current limited resources of our healthcare system.

\section{Acknowledgements}

This study received support from 2014 Endocrine Award-Diabetes Educator Award (CSEM/SCEM), sponsored by AstraZeneca.

\section{Author Disclosures}

No duality of interest declared.

\section{Author Contributions}

LF contributed to conception and research design, acquisition of data, analysis and interpretation of data, wrote the manuscript and gave final approval of the version to be published. SS guided the research study, and revised the manuscript and gave final approval of the version to be published.

\section{References}

[1] Canadian Diabetes Association. Canadian Diabetes Association (2013) Clinical Practice Guidelines for the Prevention and Management of Diabetes in Canada. Canadian Journal of Diabetes, 37, 1-3.

[2] American Diabetes Association (2016) Standards of Medical Care in Diabetes 2016. Diabetes Care, 39, S1-S7.

[3] Fan, L. and Sidani, S. (2009) Effectiveness of Diabetes Self-Management Education Intervention Elements: A Meta-Analysis. Canadian Journal of Diabetes, 33, 18-26. https://doi.org/10.1016/S1499-2671(09)31005-9

[4] Powers, M., Bardsley, J., Cypress, M., Duker, P., Funnell, M., Fischl, A.H., Maryniuk, M., Siminerio, L. and Vivian, E. (2015) Diabetes Self-Management Education and Support in Type 2 Diabetes: A Joint Position Statement of the American Diabetes Association, the American Association of Diabetes Educators, and the Academy of Nutrition and Dietetics. Diabetes Care, 38, 1372-1382. https://doi.org/10.2337/dc15-0730

[5] Brunisholz, K.D., Briot, P., Hamilton, S., et al. (2014) Diabetes Self-Management Education Improves Quality of Care and Clinical Outcomes Determined by a Diabetes Bundle Measure. Journal of Multidisciplinary Healthcare, 7, 533-542. https://doi.org/10.2147/JMDH.S69000

[6] Weaver, R.G., Hemmelgarn, B.R., Rabi, D.M., et al. (2014) Association between 
Participation in a Brief Diabetes Education Programme and Glycaemic Control in Adults with Newly Diagnosed Diabetes. Diabetic Medicine, 31, 1610-1614. https://doi.org/10.1111/dme.12513

[7] Steinsbekk, A., Rygg, L.O., Lisulo, M., Rise, M.B. and Fretheim, A. (2012) Group Based Diabetes Self-Management Education Compared to Routine Treatment for People with Type 2 Diabetes Mellitus. A Systematic Review with Meta-Analysis. BMC Health Services Research, 12, 213. https://doi.org/10.1186/1472-6963-12-213

[8] Gucciardi, E., Demelo, M., Offenheim, A. and Stewart, D.E. (2008) Factors Contributing to Attrition Behavior in Diabetes Self-Management Programs: A Mixed Method Approach. BMC Health Services Research, 8, 33.

https://doi.org/10.1186/1472-6963-8-33

[9] Gucciardi, E., Chan, V.W.S., Chuen, B.K., Fortugno, M., Horodezny, S. and Swartzack, S. (2012) Patient Factors and Perceived Barriers in Attending Diabetes Education Programs. Canadian Journal of Diabetes, 36, 214-217. https://doi.org/10.1016/j.jcjd.2012.07.009

[10] Sidani, S., Fox, M., Streiner, D.L., Miranda J., Fredericks, S. and Epstein, D. (2015) Examining the Influence of Treatment Preferences on Attrition, Adherence and Outcomes: A Protocol for a Two-Stage Partially Randomized Trial. BMC Nursing, 14, 1-8. https://doi.org/10.1186/s12912-015-0108-4

[11] Sidani, S., Epstein, D.R., Bootzin, R.R., Moritz, P. and Miranda, J. (2009) Assessment of Preferences for Treatment: Validation of a Measure. Research in Nursing \& Health, 32, 419-431. https://doi.org/10.1002/nur.20329

[12] Sidani, S., Epstein, D. and Miranda, J. (2006) Eliciting Patient Treatment Preferences: A Strategy to Integrate Evidence-Based and Patient-Centered Care. Worldviews on Evidence-Based Nursing, 3, 116-23. https://doi.org/10.1111/j.1741-6787.2006.00060.x

[13] Sidani, S., Miranda, J., Epstein, D. and Fox, M. (2009) Influence of Treatment Preferences on Validity: A Review. Canadian Journal of Nursing Research, 41, 52-67.

[14] Gucciardi, E., DeMelo, M., Offenheim, A. and Stewart, D. (2008) Factors Contributing to Attrition Behavior in Diabetes Self-Management Programs: A Mixed Method Approach. BMC Health Services Research, 8, 1-11. https://doi.org/10.1186/1472-6963-8-33

[15] Whittemore, R. (2007) Culturally Competent Interventions for Hispanic Adults with Type 2 Diabetes: A Systematic Review. Journal of Transcultural Nursing, 18, 157-166. https://doi.org/10.1177/1043659606298615

[16] Houle, J., Villaggi, B., Beaulieu, M.D., Lespérance, F., Rondeau, G. and Lambert, J. (2013) Treatment Preferences in Patients with First Episode Depression. Journal of Affective Disorders, 147, 94-100. https://doi.org/10.1016/j.jad.2012.10.016

[17] Awad, M.A., Shapiro, S.H., Lund, J.P. and Feine, J.S. (2000) Determinants of Patients' Treatment Preferences in a Clinical Trial. Community Dentistry and Oral Epidemiologh, 28, 119-125. https://doi.org/10.1034/j.1600-0528.2000.028002119.x

[18] Dwight-Johnson, M., Sherbourne, C., Liao, D. and Wells, K. (2000) Treatment Preferences Among Depressed Primary Care Patients. Journal of General Internal Medicine, 15, 527-534. https://doi.org/10.1046/j.1525-1497.2000.08035.x

[19] Chou, C.P. and Bentler, P.M. (1995) Estimates and Tests in Structural Equation Modeling. In: Hoyle, R.H., Ed., Structural Equation Modeling. Issues and Application, SAGE Publications, Newbury, 37-55.

[20] Baig, A.A., Locklin, C.A., Wilkes, A.E., et al. (2012) “One Can Learn from Other 
People's Experiences": Latino Adults' Preferences for Peer-Based Diabetes Interventions. Diabetes Educator, 38, 733-741. https://doi.org/10.1177/0145721712455700

[21] Sarkar, U., Piette, J., Gonzales, R., Lessler, D., et al. (2008) Preferences for SelfManagement Support: Findings from a Survey of Diabetes Patients in Safety-Net Health Systems. Patient Education and Counseling, 70, 102-110. https://doi.org/10.1016/j.pec.2007.09.008

[22] Gorter, K.J., Tuytel, G.H., de Leeuw, J.R.J., et al. (2010) References and Opinions of Patients with Type 2 Diabetes on Education and Self-Care: A Cross-Sectional Survey. Diabetic Medicine, 27, 85-91. https://doi.org/10.1111/j.1464-5491.2009.02886.x

[23] King, M., Nazzareth, I., Lampe, F., Bower, P., Chandler, M., Morou, M., Sibbald, B. and Lai, R. (2005) Impact of Participant and Physician Intervention Preferences on Randomized Trials A Systematic Review. Journal of the American Medical Association, 293, 1089-1099. https://doi.org/10.1001/jama.293.9.1089

[24] Macias, C., Barreira, P., Hargreaves, W., Bickman, L., Fisher, W. and Aronson, E. (2005) Impact of Referral Source and Study Applicants' Preference for Randomly Assigned Service on Research Enrollment, Service Engagement, and Evaluation Outcomes. American Journal of Psychiatry, 162, 781-787.

https://doi.org/10.1176/appi.ajp.162.4.781

[25] Purnell, T.S., Joy, S., Little, E, Bridges J, and Maruthur, N. (2014) Patient Preferences for Noninsulin Diabetes Medications: A Systematic Review. Diabetes Care, 37, 2055-2062. https://doi.org/10.2337/dc13-2527

[26] Hauber, A.B., Mohamed, A.F., Johnson, F.R. and Falvey, H. (2009) Treatment Preferences and Medication Adherence of People with Type 2 Diabetes Using Oral Glucose-Lowering Agents. Diabetic Medicine, 26, 416-424. https://doi.org/10.1111/j.1464-5491.2009.02696.x

[27] Joy, S.M., Little, E., Marthur, N.M., Purnell, T.S. and Bridges, J.F.P. (2013) Patient Preferences for the Treatment of Type 2 Diabetes: A Scoping Review. PharmacoEconomics, 31, 877-892. https://doi.org/10.1007/s40273-013-0089-7

[28] Brown, S.A. (1992) Meta-Analysis of Diabetes Patient Education Research: Variations in Intervention Effects across Studies. Research in Nursing \& Health, 15, 409-419. https://doi.org/10.1002/nur.4770150603

[29] Mulcahy, K., Maryniuk, M., Peeples, M., Peyrot, M., Tomky, D., Weaver, T. and Yarborough, T. (2003) Standards for Outcomes Measurement of Diabetes SelfManagement Education. Position Statement. The Diabetes Educator, 29, 804-816. https://doi.org/10.1177/014572170302900509

[30] Irons, B.K., Vickers, P., Esperat, C., Valdez, G.M., Dadich, K.A., Boswell, C. and Cannon, S. (2007) The Need for a Community Diabetes Education Curriculum for Healthcare Professionals. Journal of Continuing Education in Nursing, 35, 227-231. https://doi.org/10.3928/00220124-20070901-07

[31] Zheng, Y., Wu, L., Su, Z. and Zhou, Q. (2014) Development of a Diabetes Education Program Based on Modified AADE Diabetes Education Curriculum. International Journal of Clinical and Experimental Medicine, 7, 758-763.

[32] Jusko Friedman, A., Cosby, R., Boyko, S., Hatton-Bauer, J., Turnbull, G. and the Patient Education Panel (2009) Effective Teaching Strategies and Methods of Delivery for Patient Education. Evidence-Based Series 20-2 IN REVIEW. https://www.cancercare.on.ca/common/pages/UserFile.aspx?fileId=60065

[33] Adams, R. (2010) Improving Health Outcomes with Better Patient Understanding and Education. Risk Management and Healthcare Policy, 3, 61-72.

https://doi.org/10.2147/RMHP.S7500 
[34] Theis, S.L. and Johnson, J.H. (1995) Strategies for Teaching Patients: A Meta-Analysis. Clinical Nurse Specialist, 9, 100-120. https://doi.org/10.1097/00002800-199503000-00010

[35] Tang, T., Funnell, M. and Anderson, R. (2006) Group Education Strategies for Diabetes Self-Management. Diabetes Spectrum, 19, 100-105. https://doi.org/10.2337/diaspect.19.2.99

[36] Hwee, J., Cauch-Dudek, K., Victor, C., Ng, R. and Shah, B. (2014) Diabetes Education through Group Classes Leads to Better Care and Outcomes than Individual Counselling in Adults: A Population-Based Cohort Study. Canadian Journal of Public Health, 105, 192-197. https://doi.org/10.17269/cjph.105.4309

[37] Rickheim, P., Weaver, T., Flader, J. and Kendall, D. (2002) Assessment of Group versus Individual Diabetes Education: A Randomized Study. Diabetes Care, 25, 269-274. https://doi.org/10.2337/diacare.25.2.269

[38] Duke, S.A., Colagiuri, S. and Colagiuri, R. (2009) Individual Patient Education for People with Type 2 Diabetes Mellitus. The Cochrane Database of Systematic Reviews, 21, CD005268. https://doi.org/10.1002/14651858.CD005268.pub2

[39] Norris, S.L., Lau, J. and Smith, C.H. (2002) Self-Management Education for Adults with Type 2 Diabetes: A Meta-Analysis of the Effect on Glycemic Control. Diabetes Care, 25, 1159-1171. https://doi.org/10.2337/diacare.25.7.1159

[40] Kulzer, B., Hermanns, N. and Reinhecker, H. (2007) Effects of Self-Management Training in Type 2 Diabetes: A Randomized Prospective Trial. Diabetic Medicine, 24, 415 423. https://doi.org/10.1111/j.1464-5491.2007.02089.x

[41] Krishna, S. and Boren, S. (2008) Diabetes Self-Management Care via Cell Phone: A Systematic Review. Journal of Diabetes Science Technology, 2, 509-517. https://doi.org/10.1177/193229680800200324

[42] Goode, A.D., Winkler, E.A., Lawler, S.P., Reeves, M.M., Owen, N. and Eakin, E.G., (2011) A Telephone-Delivered Physical Activity and Dietary Intervention for Type 2 Diabetes and Hypertension: Does Intervention Dose Influence Outcomes? American Journal of Health Promotion, 25, 257-263. https://doi.org/10.4278/ajhp.090223-QUAN-75

[43] Goode, A.D., Winkler, E.A., Reeves, M.M. and Eakin, E.G. (2015) Relationship between Intervention Dose and Outcomes in Living Well with Diabetes-A Randomized Trial of a Telephone-Delivered Lifestyle-Based Weight Loss Intervention. American Journal of Health Promotion, 30, 120-129. https://doi.org/10.4278/ajhp.140206-QUAN-62

[44] Agurs-Collins, T.D., Kumanyika, S.K., Ten Have, T.R., et al. (1997) A Randomized Controlled Trial of Weight Reduction and Exercise for Diabetes Management in Older African-American Subjects. Diabetes Care, 20, 1503-1511. https://doi.org/10.2337/diacare.20.10.1503

[45] Fisher, E.B., Brownson, C.A., O’Toole, M.L., et al. (2007) Ongoing Follow-Up and Support for Chronic Disease Management in the Robert Wood Johnson Foundation Diabetes Initiative. Diabetes Educator, 33, 201S-207S.

https://doi.org/10.1177/0145721707304189

[46] Fisher, E.B., Thorpe, C., DeVellis, B.M., et al. (2007) Healthy Coping, Negative Emotions and Diabetes Management: A Systematic Review and Appraisal. Diabetes Educator, 33, 1080-1103. https://doi.org/10.1177/0145721707309808

[47] Fisher, E.B., Brownson, C.A., O’Toole, M.L., et al. (2007) Ongoing Follow-Up and Support for Chronic Disease Management in the Robert Wood Johnson Foundation Diabetes Initiative. Diabetes Educator, 33, 201S-207S. 
https://doi.org/10.1177/0145721707304189

[48] Mensing, C.R. and Norris, S.L. (2003) Group Education in Diabetes: Effectiveness and Implementation. Diabetes Spectrum, 16, 96-103.

https://doi.org/10.2337/diaspect.16.2.96

[49] Sidelinger, R.J, Bolen, D.M., Frisby, B.N. and McMullen, A.L. (2012) Instructor Compliance to Student Requests: An Examination of Studentto-Student Connectedness as Power in the Classroom. Communication Education, 61, 290-308. https://doi.org/10.1080/03634523.2012.666557

[50] Peyrot, M. and Rubin, R.R. (2008) Access to Diabetes Self-Management Education. Diabetes Educator, 34, 90-97. https://doi.org/10.1177/0145721707312399

[51] Gucciardi, E., Chan, V.W., Fortugno, M., Khan, S., Horodezny, S. and Swartzack, S.S. (2011) Primary Care Physician Referral Patterns to Diabetes Education Programs in Southern Ontario, Canada. Canadian Journal of Diabetes, 35, 26-268. https://doi.org/10.1016/S1499-2671(11)53009-6

[52] Shaw, K., Killeen, M., Sullvian, E. and Bowman, P. (2011) Disparities in Diabetes Self-Management Education for Uninsured and Underinsured Adults. Diabetes Educator, 37, 813-819. https://doi.org/10.1177/0145721711424618

[53] Cauch-Dudek, K., Victor, J.C., Sigmond, M. and Shah, B.R. (2013) Disparities in Attendance at Diabetes Self-Management Education Programs after Diagnosis in Ontario, Canada: A Cohort Study. BMC Public Health, 13, 85. https://doi.org/10.1186/1471-2458-13-85

[54] Active Learning Classrooms: Creative Spaces for Innovative Pedagogy at the University of Victoria.

https://www.uvic.ca/vpacademic/assets/docs/resources/classroominfrastructure/Act iveLearningClassrooms_UVic.pdf

[55] Centre for the Enhancement of Learning and Teaching (1998) Team Teaching. City University of Hong Kong. http://teaching.polyu.edu.hk/datafiles/R27.html

[56] American Association of Diabetes Educators (2010) A Sustainable Model of Diabetes Self-Management Education/Training Involves a Multi-Level Team That Can Include Community Health Workers.

https://www.diabeteseducator.org/docs/default-source/legacy-docs/_resources/pdf/r esearch/community_health_workers_white_paper.pdf?sfvrsn $=2$ 